
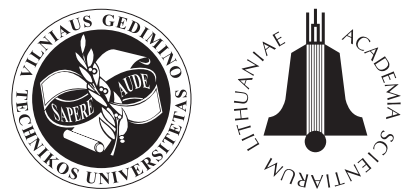

TRANSPORT

2010

25(4): $357-360$

\title{
THEORETICAL INVESTIGATION INTO EXHAUST GAS ENERGETIC UTILISATION
}

\author{
Ádám Török ${ }^{1}$, Norbert Stubán ${ }^{2}$ \\ ${ }^{1}$ Dept of Transport Economics, Budapest University of Technology and Economics, \\ Bertalan Lajos str. 2, H-1111 Budapest, Hungary \\ ${ }^{2}$ Dept of Electronics Technology, Budapest University of Technology and Economics, \\ Goldmann György sqr. 3, V2.228, H-1111 Budapest, Hungary \\ E-mails: ${ }^{1}$ atorok@kgazd.bme.hu; ${ }^{2}$ stuban@ett.bme.hu
}

Received 13 February 2010; accepted 15 November 2010

\begin{abstract}
Sustainable development is a kind of development where the pace of technical development, the satiation of increasing supply and the raw materials and resources of the Earth are poised so that the rate of living and the opportunities of the future generations should not decline. For this reason, transportation systems must be developed and the effectiveness of transportation service must be increased while environmental pollution must be decreased or prevented. Vehicles are burning fuels inefficiently. There are two options of decreasing environmental impacts - one is to reduce fuel consumption while another is to do it in a more acceptable way increasing efficiency. There is justifiable demand put forward by the society to moderate environmental impacts caused by road transportation. This article deals with modelling the energetic utilisation of exhaust gas.
\end{abstract}

Keywords: energetic utilisation, exhaust gas, heat, Seebeck effect, Peltier.

\section{Introduction}

In the last few thousand years, nature has given a stable base of living and almost infinite supply to reserve the biosphere to humanity. In the early ages, humanity made changes to the environment with limited technology, but the rate was infinitesimal compared to the size of the natural environment. Global changes were not detected. In the last two or three hundred years, there has been an explosion in the development of the industrial and technical sector that supplied people with a multiplied set of tools to encroach nature.

Motorization has been developed so dynamically that the air, soil, water pollution is considerable (Tánczos and Török 2007; Kugelevičius et al. 2007; Baltrenas et al. 2008; Kuprys et al. 2009; Török 2009; Kovács and Török 2010, etc.) to the amounts of those found on Earth (see Fig. 1). Sustainable development is a kind of development where the pace of technical development, the satiation of increasing supply and the raw materials and resources of the Earth are poised so that the rate of living and the opportunities of the future generations should not decline. Transportation cannot be replaced because it is a part of the production chain. Societies are horizontally and vertically differential. The manpower, stock, semi finished and finished products must be transported.

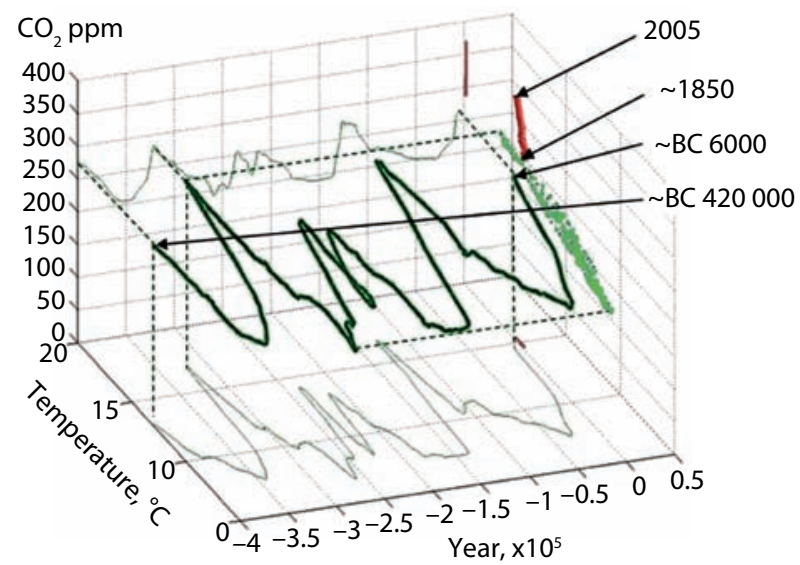

Fig. 1. Average atmospherical $\mathrm{CO}_{2}$ and average Earth temperature complex time series (Tánczos and Török 2007)

The importance of the transportation sector is indicated by sector production which is $10 \%$ of the GDP of the European Union and more than 10 million people are working in this sector. One of the most emphasized goals of the transport policy of the European Union is sustainable mobility. Trends in almost all sectors of economy will affect the transport sector. In other words, growth 
in economy automatically leads to growth in transport. There cannot be economic growth without the availability of transport. The role of economy has always been the creation and distribution of wealth. Therefore, the effectiveness of transportation service must be increased while environmental pollution must be decreased or prevented. A solution could be an increase in energetic utilisation fuels or an increase in the energetic efficiency of vehicles (Mockus et al. 2006). Therefore, using the waste energy of exhaust gas is a very important issue. The authors is aimed at investigating the theoretical possibilities of exhaust gas energetic utilisation.

\section{Heat to Electricity Converters}

There are several possibilities of transforming heat to electricity. One could be the usage of turbo generators. In the majority of car engines, waste heat is removed through the radiator using a coolant and then released to the ambient. Significant heat is also released through the exhaust system also. In case of high-performance engines, exhaust heat is used either for turbo-charging or supercharging. A turbocharger uses a turbine attached to the exhaust system, whereas a supercharger is attached directly to the engine to run a compressor. A number of other techniques, mostly conceptual, have been proposed to recover the waste heat of an automobile engine (Talom and Beyene 2009):

- metal hydride systems;

- zeolite systems;

- thermoacoustic systems;

- absorption systems;

- thermoelectric devices.

Instead of that, the authors investigated the use of the Peltier element due to better suitability to the exhaust system. Peltier elements used in a power generator mode are based on Seebeck effect. The development of a thermoelectric (TE) device arguably began in the early 19th century (DiSalvo 1999). In a conceptual system, electrical power is extracted from hot exhaust gas applying Seebeck device. The greatest shortcoming while using Peltier thermoelectric devices is their poor thermal efficiency (Innovative Waste Heat Recovery... 2008).

Thomas Johann Seebeck accidentally discovered the thermocouple in 1821. He experimentally determined that voltage exists between the two ends of a conductor when the conductor's ends are at different temperatures. His work showed that voltage is proportional to temperature difference. His discovery soon became the basis of the 'thermocouple' which is one of the most popular and cost effective temperature sensors today.

Open-circuit voltage between conductor ends was proportional to temperature difference $\left(T_{1}-T_{2}\right)$ as shown in Eq. (1):

$$
U_{12}=S_{a} \cdot\left(T_{1}-T_{2}\right)
$$

where: $U_{12}$ - voltage generated by the Peltier element; $S_{a}$ - the Seebeck coefficient defined as the 'thermoelectric power' of material (see Table 1 ); $T_{1}$ - temperature on the one side of the Peltier element; $T_{2}$ - temperature on the other side of the Peltier element.
As the first step of theoretical investigation based on Eq. $1, T_{1}$ and $T_{2}$ were measured for calculating $S_{a}$ with different load resistances. The Peltier element with $50 \mathrm{~W}$ nominal power was placed in a thermally isolated chamber. To reach sufficient and fast heat, transfer heat sinks were applied to both sides of the Peltier element. Heat sink on the warm side was accessible from the outside of the chamber as can be seen in Fig. 2.

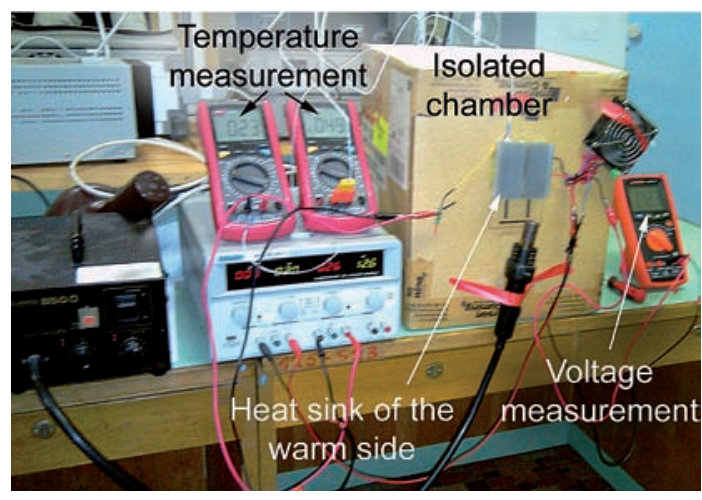

Fig. 2. Measurement setup with thermo meters, a voltage meter, a heating system and the isolated chamber

The heat sink of the cold side was placed inside the chamber and cooled by $\mathrm{H}_{2} \mathrm{O}$ ice. Different temperature values were forced to the sides of the Peltier element. The temperature of both sides was measured simultaneously. By different temperature values, nascent voltage on load resistance was measured.

The results of the measurement series can be seen in Fig. 3. A linear function between resistance $[\Omega]$ and voltage [V] can be observed as it was expected from Eq. (1). The gradients of lines need to be equal to Seebeck coefficients. A linear regression was applied to the measured data. In case of all measurement series, $R^{2}$ is over 0.99 which means a very good fit. The determined Seebeck coefficients can be seen in Table 1 .

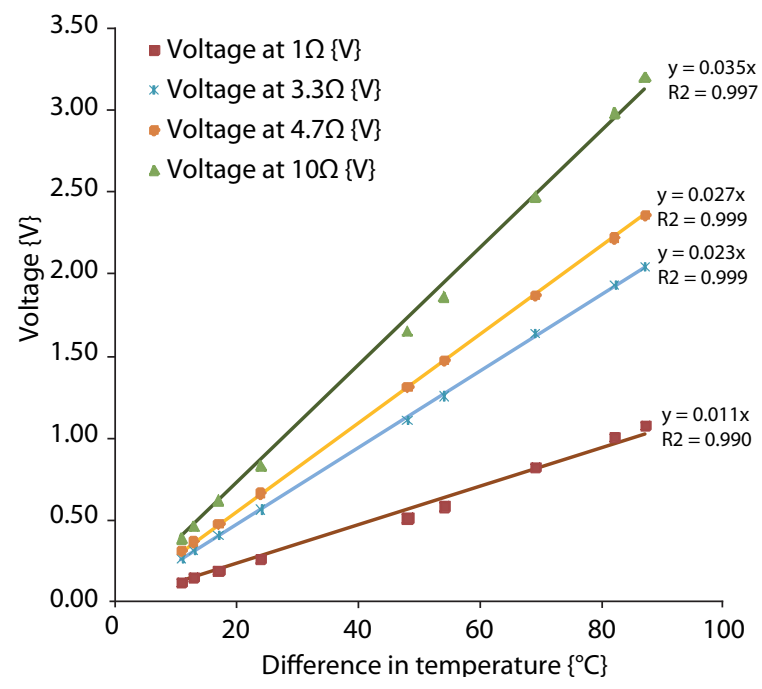

Fig. 3. A voltage function of the thermocouple considering difference in temperature (source: own calculation) 
Table 1. Determination of the Seebeck coefficient

\begin{tabular}{ccccc}
\hline$\Delta \mathrm{T}\left[{ }^{\circ} \mathrm{C}\right]$ & $\mathrm{S}_{\mathrm{a} ; 1 \Omega}\left[\frac{\mathrm{V}}{{ }^{\circ} \mathrm{C}}\right]$ & $\mathrm{S}_{\mathrm{a} ; 3.3 \Omega}\left[\frac{\mathrm{V}}{{ }^{\circ} \mathrm{C}}\right]$ & $\mathrm{S}_{\mathrm{a} ; 4.7 \Omega}\left[\frac{\mathrm{V}}{{ }^{\circ} \mathrm{C}}\right]$ & $\mathrm{S}_{\mathrm{a} ; 10 \Omega}\left[\frac{\mathrm{V}}{{ }^{\circ} \mathrm{C}}\right]$ \\
\hline 11 & 0.011 & 0.021 & 0.028 & 0.035 \\
\hline 13 & 0.012 & 0.020 & 0.028 & 0.035 \\
\hline 17 & 0.011 & 0.020 & 0.028 & 0.036 \\
\hline 24 & 0.011 & 0.020 & 0.027 & 0.035 \\
\hline 48 & 0.011 & 0.019 & 0.027 & 0.034 \\
\hline 54 & 0.011 & 0.019 & 0.027 & 0.034 \\
\hline 69 & 0.012 & 0.019 & 0.027 & 0.036 \\
\hline 82 & 0.012 & 0.019 & 0.027 & 0.036 \\
\hline 87 & 0.012 & 0.019 & 0.027 & 0.037 \\
\hline AVG & 0.011 & 0.02 & 0.027 & 0.035 \\
\hline
\end{tabular}

source: measurement was done at BME

Department of Electronics Technology

$$
P=\frac{\left(U_{12}\right)^{2}}{R}=\frac{\left(\Delta T \cdot S_{A}\right)^{2}}{R}=\Delta T^{2} \cdot \frac{S_{A}^{2}}{R},
$$

where: $P$ - power generated by the Peltier element (Fig. 4); $R$ - load resistance.

In semiconductors, temperature differences induce majority carriers (holes for $p$-type or electrons for $n$ type) to diffuse from a hotter area of the gradient to a cooler area. The movement of carriers creates DC potential which is negative voltage for electrons and positive voltage for holes. Current can flow through the material if load is attached. Due to numerous process variables related to producing semiconductor materials such as doping densities and crystalline phase, there is no way to directly calculate the Seebeck coefficient that must be determined experimentally. The Seebeck coefficient of semiconductors and metals is of interest for thermoelectric power generation technology.

The generated power of the Peltier element from the value of load resistance and the measured voltage

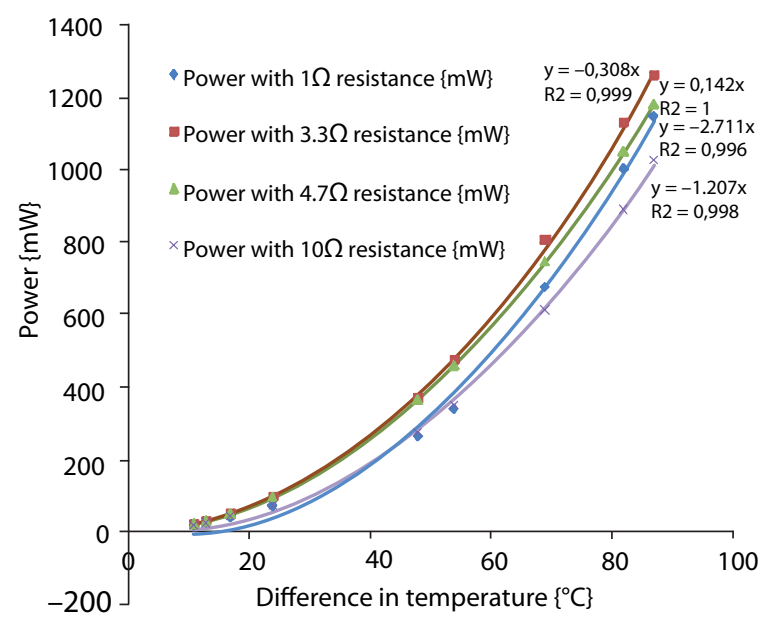

Fig. 4. A power function of the thermocouple considering difference in temperature (source: own calculation) was also calculated. In Fig. 4, the quadratic function (Eq. (2)) between difference in temperature $\left[{ }^{\circ} \mathrm{C}\right]$ and power $[\mathrm{mW}]$ can be observed.

The result of the measurement shows that the thermocouple of $50 \mathrm{~W}$ nominal power with $87^{\circ} \mathrm{C}$ temperature difference can generate $1.2 \mathrm{~W}$ power. Therefore, the efficiency of the process is approximately $2.4 \%$.

The conversion from heat to useful electric power is a promising method for increasing the efficiency of automobiles where waste exhaust heat can be used to generate electricity for the alternator. This technique is currently being researched by several car companies such as BMW who claims an increase in 5\% in fuel economy (Cywar et al. 2009). The aim of this investigation is not to increase fuel efficiency but to decrease the emission of diesel engines.

\section{Energetic Investigation into Passenger Cars}

Basically, compression engines have been investigated because their exhaust gas temperature has smaller deviation than spark ignition engines (Juostas and Janulevičius 2009). Compression engines are lead by diesel oil which has $34 \mathrm{MJ} \cdot \mathrm{l}^{-1}$ of lower heating value (LHV). Theoretically, when burning diesel oil in compression engines, we can have approx $10.2 \mathrm{MJ} \cdot l^{-1}$ of energy in exhaust gas (see Fig. 5).

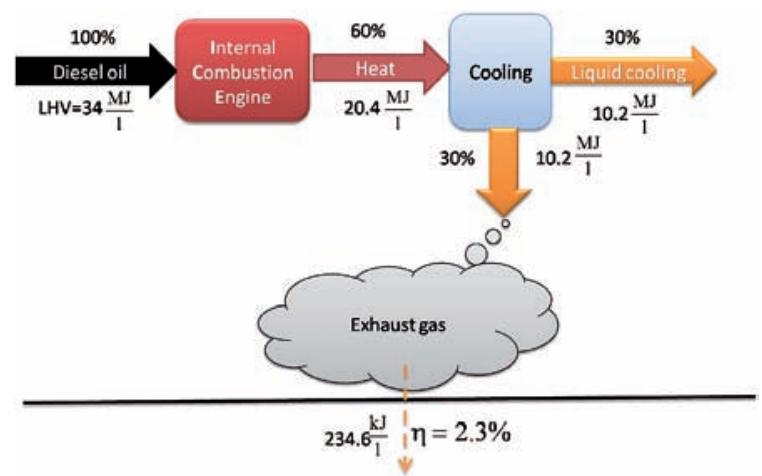

Fig. 5. An energetic balance of diesel oil (source: own research)

As Fig. 5 suggests, approximately $0.069 \mathrm{kWh} \cdot l^{-1}$ of energy can be utilised from exhaust gas (typically, $800^{\circ} \mathrm{C}$ gases have a velocity of $60 \mathrm{~m} / \mathrm{s}$ and a mass flow rate of $0.05 \mathrm{~kg} / \mathrm{s}$, thus providing enough energy for the Peltier element (TIGERS: Exhaust Gas to Electricity ... 2005) with high probability) with thermocouples.

\section{Constructional Considerations}

To determine the number of Peltier elements, difference in temperature (Fig. 6) and the required power need to be considered.

Automobile engines release a significant amount of heat to the environment. For example, Hatazawa et al. (2004) believe that as much as 35\% of thermal energy generated from combustion in an automotive engine is lost to the environment through exhaust gas and other losses. 


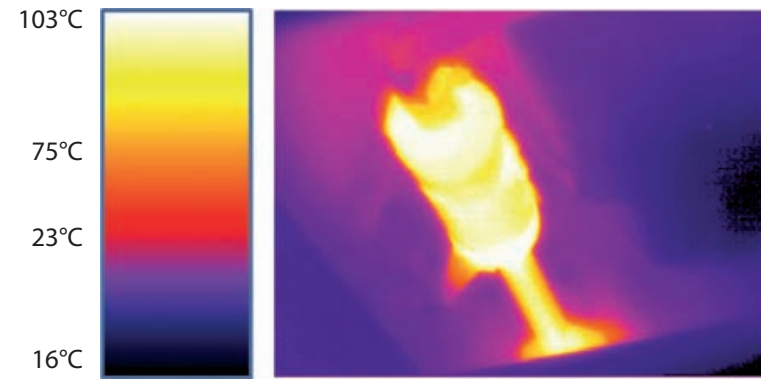

Fig. 6. A thermo picture from an exhaust system (source: own measurements at BME Jendrassik György laboratory of Department of Energy Engineering)

As indicated in Fig. 6, the gradient of temperature is $10^{\circ} \mathrm{C} \cdot \mathrm{cm}^{-1}$. As a result of our measurements, $1.2 \mathrm{~W}$ power per unit can be generated from the Peltier element. For reaching $100 \mathrm{~W}$ power, 84 units, which makes approximately $2100 \mathrm{~cm}^{2}$ of hot surface, are required. Along with produced electricity, an emission reducing unit will be used.

\section{Conclusions}

1. The author investigates the theoretical possibilities of exhaust gas energetic utilisation.

2. The authors examined the use of the Peltier element because of easier additivity to the exhaust system.

3. With reference to international literature, the authors of the article have found a linear function between resistance $[\Omega]$ and voltage $[V]$. Not only Seebeck related voltage but also maximal allowable power generated by the Peltier element is important. For this reason, the authors have performed power measurements using resistances of $1 \Omega, 3.3 \Omega, 4.7 \Omega$ and $10 \Omega$.

4. A quadratic function has been found by the measurements suitable for international literature.

5. Calculations made by the authors disclose that a thermocouple of $50 \mathrm{~W}$ nominal power with temperature difference of $87^{\circ} \mathrm{C}$ can generate $1.2 \mathrm{~W}$ power.

6. While applying several Peltier elements, enough power can be generated for using an emission reducing unit.

\section{Acknowledgements}

The authors of the article are grateful to the Laboratory of the Department of Electronics Technology and Jendrassik György Laboratory of the Department of Energy Engineering, Budapest University of Technology and Economics (BME).

This work is connected to scientific program Development of quality-oriented and harmonized $R+D+I$ strategy and functional model at BME and project Modelling and multi-objective optimization based control of road traffic flow considering social and economical aspects. These projects are supported by the New Hungary Development Plan (Project ID: TÁMOP-4.2.1/B-09/1/ KMR-2010-0002) and program CNK 78168 of OTKA.

\section{References}

Baltrènas, P.; Vaitiekūnas, P.; Vasarevičius, S.; Jordaneh, S. 2008. Modelling of motor transport exhaust gas influence on the atmosphere, Journal of Environmental Engineering and Landscape Management 16(2): 65-75. doi:10.3846/1648-6897.2008.16.65-75

Cywar, A.; Crabtree, B.; Williams, N. 2009. Seebeck Measurement Setup. Project Report ECE 4901. Available from Internet: <http://www.ee.uconn.edu/SeniorDesign/projects/ ecesd119/FinalReport.pdf $>$.

DiSalvo, F. J. 1999. Thermoelectric cooling and power generation, Science 285(5428): 703-706. doi:10.1126/science.285.5428.703

Hatazawa, M.; Sugita, H.; Ogawa, T.; Seo, Y. 2004. Performance of a thermoacoustic sound wave generator driven with waste heat of automobile gasoline engine, Transactions of the Japan Society of Mechanical Engineers: Part B 70(689): 292-299 (in Japanese).

Innovative Waste Heat Recovery and Novel Cooling Systems: Automotive Waste Heat Recovery. 2008. The Small Business Innovation Research (SBIR) program. Office of Energy Efficiency and Renewable Energy. Available from Internet: <http://www.science.doe.gov/sbir/solicitations/FY\%20 2005/26_EE1.htm>.

Juostas, A.; Janulevičius, A. 2009. Evaluating working quality of tractors by their harmful impact on the environment, Journal of Environmental Engineering and Landscape Management 17(2): 106-113. doi:10.3846/1648-6897.2009.17.106-113

Kovács, V. B.; Török, Á. 2010. Investigation on transport related biogas utilization, Transport 25(1): 77-80. doi:10.3846/ transport.2010.10

Kugelevičius, J. A.; Kuprys, A.; Kugelevičius, J. 2007. Forecasts of petroleum demand, Transport 22(1): 9-13.

Kuprys, A.; Kugelevičius, J. 2009. Possibilities of using liquefied oil gas in transport, Transport 24(1): 48-53. doi:10.3846/1648-4142.2009.24.48-53

Mockus, S.; Sapragonas, J.; Stonys, A.; Pukalskas, S. 2006. Analysis of exhaust gas composition of internal combustion engines using liquefied petroleum gas, Journal of Environmental Engineering and Landscape Management 14(1): 16-22.

Talom, H. L.; Beyene, A. 2009. Heat recovery from automotive engine, Applied Thermal Engineering 29(2-3): 439-444. doi:10.1016/j.applthermaleng.2008.03.021

Tánczos, K.; Török, A. 2007. The linkage between climate change and energy consumption of Hungary in the road transportation sector, Transport 22(2): 134-138.

TIGERS: Exhaust Gas to Electricity for Reductions in Fuel Consumption. 2005. Green Car Congress: Energy, Technologies, Issues and Policies for Sustainable Mobility. 21 September 2005. Available from Internet: <http://www.greencarcongress.com/2005/09/tigers_exhaust_.html\#trackback>.

Török, Á. 2009. Theoretical estimation of the environmental impact of biofuel mixtures, Transport 24(1): 26-29. doi:10.3846/1648-4142.2009.24.26-29 